\title{
Description of the First Four Species of the Genus Pseudogymnoascus From Antarctica
}

\section{OPEN ACCESS}

Edited by:

Veronica Molina,

Universidad de Playa Ancha, Chile

Reviewed by:

Luiz H. Rosa,

Federal University of Minas Gerais,

Brazil

Juan Antonio Ugalde,

Universidad del Desarrollo, Chile

Ramon Alberto Batista-García,

Universidad Autónoma del Estado

de Morelos, Mexico

*Correspondence:

Renato Chávez

renato.chavez@usach.c

Inmaculada Vaca

inmavaca@uchile.c

Specialty section:

This article was submitted to

Systems Microbiology,

a section of the journal

Frontiers in Microbiology

Received: 22 May 2021 Accepted: 18 October 2021 Published: 19 November 2021

Citation:

Villanueva P, Vásquez $G$

Gil-Durán C, Oliva V, Díaz A, Henríquez M, Álvarez E, Laich F

Chávez $R$ and Vaca I (2021)

Description of the First Four Species of the Genus Pseudogymnoascus

From Antarctica.

Front. Microbiol. 12:713189. doi: 10.3389/fmicb.2021.713189

\begin{abstract}
Pablo Villanueva', Ghislaine Vásquez¹, Carlos Gil-Durán', Vicente Oliva1, Anaí Díaz', Marlene Henríquez ${ }^{1}$, Eduardo Álvarez ${ }^{2}$, Federico Laich ${ }^{3}$, Renato Chávez ${ }^{4 *}$ and Inmaculada Vaca ${ }^{*}$

${ }^{1}$ Department of Chemistry, Faculty of Sciences, University of Chile, Santiago, Chile, ${ }^{2}$ Institute of Biomedical Sciences (ICBM), Mycology Unit, Faculty of Medicine, University of Chile, Santiago, Chile, ${ }^{3}$ Departamento de Protección Vegetal, Instituto Canario de Investigaciones Agrarias, Santa Cruz de Tenerife, Islas Canarias, Spain, ${ }^{4}$ Departamento de Biología, Facultad de Química y Biología, Universidad de Santiago de Chile (USACH), Santiago, Chile
\end{abstract}

The genus Pseudogymnoascus represents a diverse group of fungi widely distributed in different cold regions on Earth. Our current knowledge of the species of Pseudogymnoascus is still very limited. Currently, there are only 15 accepted species of Pseudogymnoascus that have been isolated from different environments in the Northern Hemisphere. In contrast, species of Pseudogymnoascus from the Southern Hemisphere have not yet been described. In this work, we characterized four fungal strains obtained from Antarctic marine sponges. Based on multilocus phylogenetic analyses and morphological characterizations we determined that these strains are new species, for which the names Pseudogymnoascus antarcticus sp. nov., Pseudogymnoascus australis sp. nov., Pseudogymnoascus griseus sp. nov., and Pseudogymnoascus lanuginosus sp. nov. are proposed. Phylogenetic analyses indicate that the new species form distinct lineages separated from other species of Pseudogymnoascus with strong support. The new species do not form sexual structures and differ from the currently known species mainly in the shape and size of their conidia, the presence of chains of arthroconidia, and the appearance of their colonies. This is the first report of new species of Pseudogymnoascus not only from Antarctica but also from the Southern Hemisphere.

\section{Keywords: Pseudogymnoascus, new species, Antarctica, taxonomy, multi-locus phylogenetic analyses}

\section{INTRODUCTION}

The fungal genus Pseudogymnoascus (Pseudeurotiaceae, Thelebolales, Leotiomycetes) was erected by Raillo (1929) to accommodate P. roseus and P. vinaceus, two species producing ascomata that Raillo distinguished from Gymnoascus based on differences in peridial hyphae. Unfortunately, Raillo did not formally specify a type strain for the genus. Many years later, Samson (1972) synonymized $P$. vinaceus with $P$. roseus and formally designated $P$. roseus CBS 395.65, a strain isolated from an alluvial swamp soil in Great Britain, as the neotype for the genus Pseudogymnoascus, which has been accepted to date. 
In addition to $P$. roseus, only three additional species of Pseudogymnoascus were accepted during the 20th century: P. caucasicus, P. bhattii, and P. alpinus (Cejp and Milko, 1966; Samson, 1972; Müller and von Arx, 1982). Using a polyphasic approach including molecular phylogeny analysis based on ITS and morphological characterizations, Rice and Currah (2006) described two other new species, $P$. appendiculatus and $P$. verrucosus.

The interest in Pseudogymnoascus experienced a boost in 2009 when the causal agent of white-nose syndrome (WNS), a lethal disease that affects bats in North America, was discovered to be a novel species of psychrophilic fungus that was identified at that time as Geomyces destructans (Blehert et al., 2009; Gargas et al., 2009). The discovery of the fungal origin of WNS led to intense phylogenetic studies of fungi that live in bat caves. As a result, the phylogeny of Geomyces, Pseudogymnoascus, and other close genera was reorganized, including the transference of three species from other genera to the genus Pseudogymnoascus: $P$. destructans (formerly G. destructans), P. pannorum (formerly G. pannorum), and P. carnis (formerly Sporotrichum carnis) (Minnis and Lindner, 2013). These phylogenetic studies also suggested that caves and similar environments in North America harbor several undescribed species of Pseudogymnoascus (Lorch et al., 2013; Minnis and Lindner, 2013). Indeed, three new recently described species named $P$. lindneri, $P$. turneri, and $P$. palmeri were isolated from sediment samples obtained in a mine, a railroad tunnel, and a cave, respectively (Crous et al., 2019; Crous et al., 2020). Recently, in 2020, three additional species of Pseudogymnoascus, P. shaanxiensis, P. guizhouensis, and $P$. sinensis, were described. These species were isolated from soils collected in different locations in China (Zhang et al., 2020). To our knowledge, these are the last species of the genus described to date, thus totaling only 15 accepted species of Pseudogymnoascus since 1929.

The species of the genus Pseudogymnoascus share as common characteristics the ability to produce aleurioconidia and/or arthroconidia and an optimal temperature of growth of approximately $15^{\circ} \mathrm{C}$. Concerning sexual structures, several Pseudogymnoascus species produce ascomata (Rice and Currah, 2006; Crous et al., 2019; Crous et al., 2020). However, other members of the genus, particularly those transferred from Geomyces and Sporotrichum, do not produce ascomata (Minnis and Lindner, 2013; Zhang et al., 2020).

Although genus Pseudogymnoascus had a broad geographic distribution in cold regions around the world (Gomes et al., 2018; Robicheau et al., 2019; Gupta et al., 2020; Rafiq et al., 2020), all the currently accepted species of Pseudogymnoascus were isolated from samples collected in the Northern Hemisphere, mainly in North America. In contrast, new species of Pseudogymnoascus obtained in the Southern Hemisphere have not yet been described.

Antarctica is one of the most remote and cold regions on Earth. In this continent, Pseudogymnoascus is prevalent. Numerous strains of this fungal genus have been isolated from different Antarctic environments, including terrestrial soils (Godinho et al., 2015; Gomes et al., 2018; Durán et al., 2019; Santos et al., 2020), plants (Santiago et al., 2012;
Costa Coelho et al., 2021), shallow-water and deep-sea sediments (Vieira et al., 2018; Wentzel et al., 2019; Ogaki et al., 2020a; Ogaki et al., 2021), macroalgae (Godinho et al., 2013; Furbino et al., 2014; Furbino et al., 2018), sponges (Henríquez et al., 2014), and lakes (Gonçalves et al., 2012; Ogaki et al., 2020b). These results suggest that the Antarctic environments could constitute important reservoirs for new species of Pseudogymnoascus not yet described.

Our research team is interested in the study of filamentous fungi from Antarctica. In recent years, we have gathered an important collection of fungal isolates of Antarctic origin, and according to preliminary data, several of these isolates could be new species (Henríquez et al., 2014). Thus, in this work, we described four new species of Pseudogymnoascus obtained from samples of Antarctic marine sponges, for which the names Pseudogymnoascus antarcticus, Pseudogymnoascus australis, Pseudogymnoascus griseus, and Pseudogymnoascus lanuginosus are proposed. These species represent not only the first four Pseudogymnoascus species from Antarctica but also the first four species of this fungal genus from the Southern Hemisphere.

\section{MATERIALS AND METHODS}

\section{Fungal Isolates}

The fungal isolates analyzed in this work were obtained from sponge samples collected in Fildes Bay, King George Island, South Shetland Islands, Antarctica (Henríquez et al., 2014). Sponge samples were collected at a depth of $6 \mathrm{~m}$. P. antarcticus was isolated from a sponge from the genus Tedania, P. lanuginosus was isolated from a sponge from the order Poecilosclerida, and $P$. australis and $P$. griseus were isolated from two different sponges from the genus Hymeniacidon (Henríquez et al., 2014).

The sampling was authorized by the Chilean Antarctic Institute (authorization no. FORE-LO T_15-09, issued on October 13, 2009) and carried out during the XLVI Antarctic Scientific Expedition (ECA46) in December 2009. The holotypes were deposited in the Chilean Fungal Collection (CHFC-EA) of the University of Chile (Santiago, Chile).

\section{Morphological Analyses}

The characteristics of colonies, including the presence of soluble pigments and/or exudates, the obverse and reverse colors of colonies, and the color of mycelia, were recorded after 28 days of growth on oatmeal agar (OA; Difco Laboratories), corn meal agar (CMA; Difco Laboratories), and Sabouraud agar (SBA; Difco Laboratories) at five different temperatures (5, 15, 20, 25, and $37^{\circ} \mathrm{C}$ ). In addition, colony diameters were measured every 5 days, and colonial growth rates were determined.

To induce the formation of ascomata, fungi were grown on CMA, OA, SBA, and potato dextrose agar (PDA; Difco Laboratories) at the same five temperatures mentioned above under two different light conditions: constant darkness and daily cycles of $12 \mathrm{~h}$ with fluorescent light alternating with $12 \mathrm{~h}$ of darkness. The presence of sexual structures was checked at 10 days and at 2, 4, 6, and 8 months of cultivation. 
Light microscopy images were obtained using a Leica DM 2000 LED microscope equipped with an MC170 HD camera and Leica Application Suite (LAS) v.4.8.0 software. Microscopic characteristics were studied on CMA slide cultures incubated for 7 and 14 days at $15^{\circ} \mathrm{C}$ and mounted in Shear's solution. Electron microscopy images of Pseudogymnoascus conidia were acquired with a Hitachi HT7700 transmission electron microscopy (TEM).

\section{DNA Extraction, Amplification of Markers, and Sequencing}

Each strain was grown for 3 days in CM liquid medium (GilDurán et al., 2015). After that, the mycelia were collected, and genomic DNA was isolated as previously described (Mahuku, 2004). Genomic DNA was used for the amplification of five markers using primers and PCR conditions that have been previously described (Minnis and Lindner, 2013). The markers were internal transcribed spacer (ITS), nuclear large subunit (LSU) rDNA, DNA replication licensing factor (MCM7), RNA polymerase II second largest subunit (RPB2), and translation elongation factor EF-1a (TEF1). The sequence of primers used to amplify these markers is described in Supplementary Table $\mathbf{1 .}$ The PCR products obtained were purified using a Qiaquick ${ }^{\circledR}$ PCR Purification Kit (Qiagen) and were sequenced at Macrogen Inc. (South Korea).

The sequences generated in this work were deposited in the GenBank database and their accession numbers are listed in Supplementary Table 2 .

\section{Phylogenetic Analyses}

By combining the sequences generated in this work with sequences downloaded from GenBank, a sequence dataset was generated (Supplementary Table 2). Alignments for each individual locus were performed using MAFFT v. $7^{1}$ with default parameters (Katoh and Standley, 2013). Both sequence edition and concatenation were performed using Mesquite V3.61 (Maddison and Maddison, 2019). Minnis and Lindner (2013) observed that LSU and TEF1 introns have limited phylogenetic value because they are present and scattered among unrelated members of Pseudogymnoascus. Therefore, homologous gaps corresponding to LSU and TEF1 introns were excluded. In addition, non-overlapping ends of sequences in each alignment were trimmed. Gene concordance was assessed for all generated matrices using the "hompart" command in PAUP4.0b10 (Swofford, 2002). The final alignment was deposited in TreeBASE. ${ }^{2}$

Phylogenetic analyses were performed using maximum likelihood (ML) and Bayesian inference (BI) methods. ML analyses were performed with IQ-TREE v.1.6.12 (Nguyen et al., 2015). The best-fit nucleotide substitution model for each locus was estimated using IQ-TREE's ModelFinder function (Kalyaanamoorthy et al., 2017) following the Bayesian information criterion (BIC). Bootstrap analyses were performed using the ultrafast bootstrap approximation (Minh et al., 2013) with 1,000 replicates. BI analyses were performed with MrBayes

${ }^{1}$ http://mafft.cbrc.jp/alignment/server/

${ }^{2}$ http://purl.org/phylo/treebase/phylows/study/TB2:S28862 v.3.2. (Ronquist et al., 2012). The analyses included two independent runs of 2 million generations with four chains each.

The substitution model was set to GTR + I + G, and the first $25 \%$ of samples and trees were discarded as burn-in. The remaining trees were used to construct a $50 \%$ majority rule consensus tree.

\section{RESULTS}

\section{Phylogenetic Analyses}

After the exclusion of non-overlapping ends and LSU and TEF1 introns (393 and 57 nucleotides, respectively), the concatenated alignment contained 3,152 nucleotides (ITS: 442; LSU: 931; MCM7: 503 bp; RPB2: 526, and TEF1: 750).

The best-fit evolutionary models for each locus in the ML analysis were $\mathrm{K} 2 \mathrm{P}+\mathrm{R} 2$ (ITS), TNe + R2 (LSU), K2P + I + G4 (MCM7), K2P + G4 (RPB2), and TNe + R3 (TEF1). The tree topology of the BI agreed with that of the ML tree. Therefore, only the BI tree is shown (Figure 1). The phylogenies indicated that all the new species of Pseudogymnoascus of Antarctic origin were placed in distinct branches, forming clades separated from other species, with strong bootstrap support (Figure 1). P. australis, $P$. griseus, and $P$. lanuginosus were included within the wellsupported crown group (clades A-G, PP = 1) (Figure 1). $P$. australis and $P$. griseus clustered together and were placed within clade $\mathrm{B}$, while $P$. lanuginosus was clustered as a sister taxon of clade E (Figure 1). Finally, P. antarcticus was clustered as a sister taxon to clade I, forming an independent and wellsupported lineage (Figure 1).

\section{Taxonomy}

Phylogenetic analyses based on five gene markers showed that $P$. antarcticus, $P$. australis, $P$. griseus, and $P$. lanuginosus are phylogenetically distinct from the other known species of the genus Pseudogymnoascus. Furthermore, the new taxa can be distinguished from each other and all other Pseudogymnoascus species based on morphology. These results provide support to describe the four taxa analyzed in this work as new species as follows.

\section{Pseudogymnoascus antarcticus Vaca \& R. Chávez, sp. nov.}

MycoBank number: MB 838958 (Figures 2, 3).

Etymology: The name refers to Antarctica, the continent where this species was isolated.

Typus: Antarctica, South Shetland archipelago, King George Island, Fildes Bay, from a marine sponge, 7 Dic. 2009, I. Vaca F09T2-1 (holotype CHFC-EA 569, stored in a metabolically inactive state in Chilean Fungal Collection).

Description: Hyphae forming bundles with two to six hyphae oriented in parallel, branched, septate, hyaline, smooth, 1.8$2.1 \mu \mathrm{m}$ wide. Fertile hyphae bearing arthroconidia and/or aleurioconidia, sessile, or stalked. Conidiophores sparse, solitary, erect, hyaline, smooth, narrow, arising laterally from the hyphae, usually bearing verticils of two to four branches, arising from 


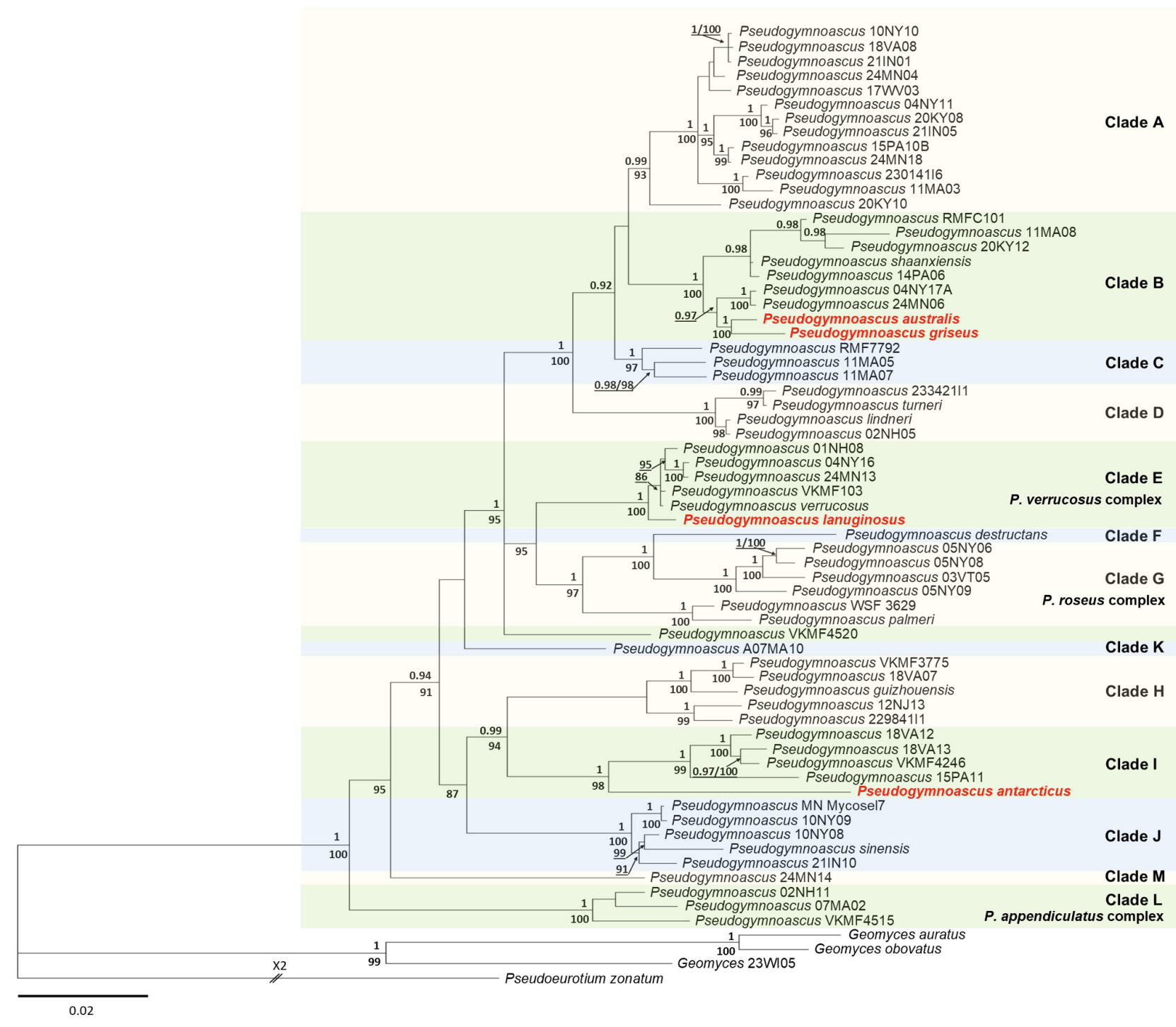

FIGURE 1 | Bayesian inference phylogenetic tree of Pseudogymnoascus generated from the concatenated dataset of five loci (ITS, LSU, TEF1, RPB2, and MCM7). Bayesian posterior probabilities (BPPs) are indicated above branches and significant ML bootstrap (BS) values below branches. Only clades that received $\geq 80 \%$ BS and $\geq 0.95$ BPP simultaneously were considered strongly supported and presented at the nodes. Clades are identified using clade nomenclature (A to M) formally defined by Minnis and Lindner (2013). The scale bar indicates 0.02 nucleotide changes per site. The new species are highlighted in bold and red.

the stipe at an acute angle. Conidia sparse in SBA, more abundant in CMA, intercalary or terminal, off-white en masse, hyaline, microtuberculate. Aleurioconidia obovoid to subglobose, occasionally pyriform or clavate, with a broad truncate basal scar, 3.3-5.2 $\times 2.4-3.4 \mu \mathrm{m}(a v=4.0 \times 2.8 \mu \mathrm{m}, n=50)$, in conidiophores separated by connective cells. Intercalary conidia are similar to arthroconidia in shape and size. Arthroconidia intercalary, subglobose to elongate and barrel-shaped, separated by connective cells that undergo rhexolysis, occasionally bearing sessile conidia, 3.6-6.7 $\times 1.9-2.1 \mu \mathrm{m}($ av $=5.2 \times 1.9 \mu \mathrm{m}, n=50)$. Ascomata absent.

Culture characteristics: On OA, colonies reach $35 \mathrm{~mm}$ in diameter after 28 days at $15^{\circ} \mathrm{C}$, round shape, slightly irregular, dense and slightly umbonate, floccose, with radial grooves, olive green to gray, margin filamentous and white, transparent droplets of exudate on the surface of the colony, diffusible pigments absent; reverse brown. On CMA, colonies reach $46 \mathrm{~mm}$ in diameter after 28 days at $15^{\circ} \mathrm{C}$, appressed, colorless, whitish at the center, consisting of immersed and hyaline hyphae, diffusible pigments and/or exudates absent; reverse colorless. On SBA, colonies reach $35 \mathrm{~mm}$ in diameter after 28 days at $15^{\circ} \mathrm{C}$, round shape, sometimes irregular, velvety, with radial grooves and smooth center, pale pink with peach color at the center, soluble pigment yellow, exudates absent; reverse orange. Growth occurs in a range of temperatures on OA, CMA, and SBA. Optimum growth was observed at 15 and $20^{\circ} \mathrm{C}$, and more reduced growth was observed at 5 and $25^{\circ} \mathrm{C}$. At $37^{\circ} \mathrm{C}$, small pinpoint colonies are observed. 


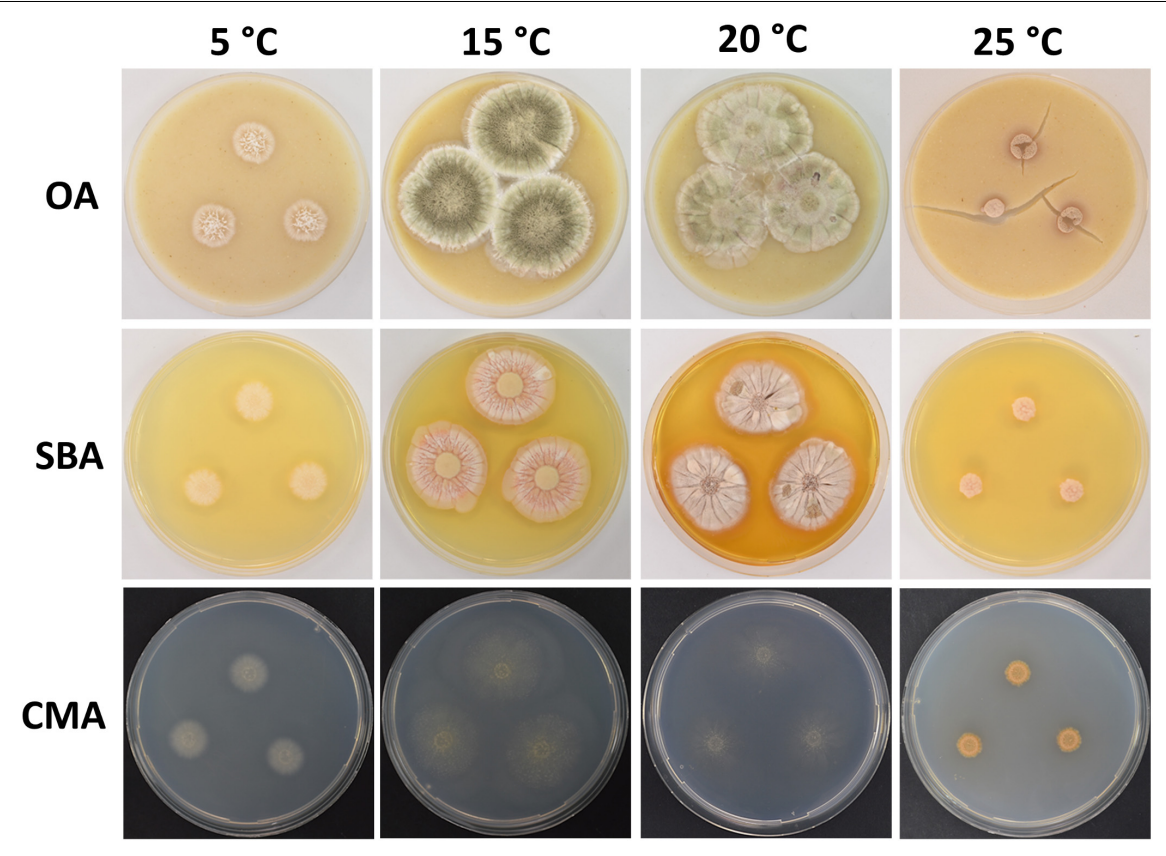

FIGURE 2 | Colony morphology of Pseudogymnoascus antarcticus sp. nov. grown on OA, SBA, and CMA media at $5,15,20$, and $25^{\circ} \mathrm{C}$ after 28 days of incubation. The cracked agar observed in $\mathrm{OA}$ at $25^{\circ} \mathrm{C}$ was not produced by a technical pitfall, but was produced by the growth of the fungus. Apparently, under these conditions, the fungus extracts most moisture, contracts agar, and cracks it. This was always observed in this medium at this temperature.

GenBank accession numbers: ITS $=$ JX845280, LSU $=$ MN417282, MCM7 = MN432493, TEF1- $\alpha=$ MN418131, RPB2 = MN418135.

Notes: In previous phylogenetic analyses using North American strains, Minnis and Lindner (2013) proposed multiple clades of Pseudogymnoascus (clades A to M). Figure 1 shows that clade I harbors four strains (15PA11, 18VA12, 18VA13, and VKM F-4246) that remain unidentified species to date (Minnis and Lindner, 2013; Leushkin et al., 2015). P. antarcticus represents the most basal branch within clade I, forming an independent lineage with strong support (Figure 1). The closest known species to $P$. antarcticus is $P$. guizhouensis, which is a member of the neighboring clade $\mathrm{H}$ (Zhang et al., 2020). The absence of ascomata and the size and shape of the terminal conidia are characteristics shared in both species. However, $P$. guizhouensis and P. antarcticus have marked morphological differences. $P$. antarcticus has fertile hyphae that break into chains of arthroconidia, while $P$. guizhouensis lacks arthroconidia. In addition, $P$. antarcticus has subglobose to elongate, barrelshaped intercalary conidia, while the intercalary conidia of $P$. guizhouensis are cuneiform, barrel-shaped, and markedly smaller than the intercalary conidia of $P$. antarcticus. Finally, conidia of $P$. antarcticus are microtuberculate, while conidia of $P$. guizhouensis are smooth or echinulate.

\section{Pseudogymnoascus australis Vaca \& R. Chávez, sp. nov.}

MycoBank number: MB838968 (Figures 4, 5).

Etymology: The epithet australis means Southern, referring to the region of Earth in which this fungus was isolated.
Typus: Antarctica, South Shetland archipelago, King George Island, Fildes Bay, from a marine sponge, 7 Dic. 2009, I. Vaca F09T18-3 (holotype CHFC-EA 567, stored in a metabolically inactive state in Chilean Fungal Collection).

Description: Hyphae forming bundles with three to five hyphae oriented in parallel, branched, septate, hyaline, smooth, 1.2-2.0 $\mu \mathrm{m}$ wide. Some lateral hyphae end in chains of barrelshaped arthroconidia, sometimes bearing aleurioconidia, sessile, or stalked. Conidiophores abundant, solitary, erect, frequently geniculate, or arising in acute angles with the main axis, hyaline, smooth, usually bearing verticils of two to four branches arising from the stipe at an acute angle. Conidia sparse in SBA, more abundant in CMA, intercalary or terminal, offwhite en masse, hyaline, smooth to rough, irregularly warty. Aleurioconidia obovoid to subglobose, occasionally pyriform or clavate, with a broad truncate basal scar, 3.4-5.6 $\times 2.3-3.3 \mu \mathrm{m}$ ( $a v=4.2 \times 2.8 \mu \mathrm{m}, n=50)$, in conidiophores separated by connective cells; intercalary conidia similar to arthroconidia in shape and size. Arthroconidia intercalary subglobose to elongate and barrel-shaped, 3.4-6.8 $\times 1.3-3.1 \mu \mathrm{m}(a v=4.7 \times 2.1 \mu \mathrm{m}$, $n=50$ ), separated by connective cells that undergo rhexolysis, occasionally bearing sessile conidia; arthroconidia formed in hyphal junctions are L- or boot-shaped. Ascomata absent.

Culture characteristics: On OA, colonies reach $48 \mathrm{~mm}$ in diameter after 28 days at $15^{\circ} \mathrm{C}$, irregular, partially serrated, slightly raised, floccose, grayish, white at the outermost part of the colony, margin white and filiform, abundant exudates in the form of transparent, cinnamon-color droplets of large size, diffusible pigments absent; reverse brown. On CMA, colonies reach $44 \mathrm{~mm}$ in diameter after 28 days at $15^{\circ} \mathrm{C}$, filamentous, 

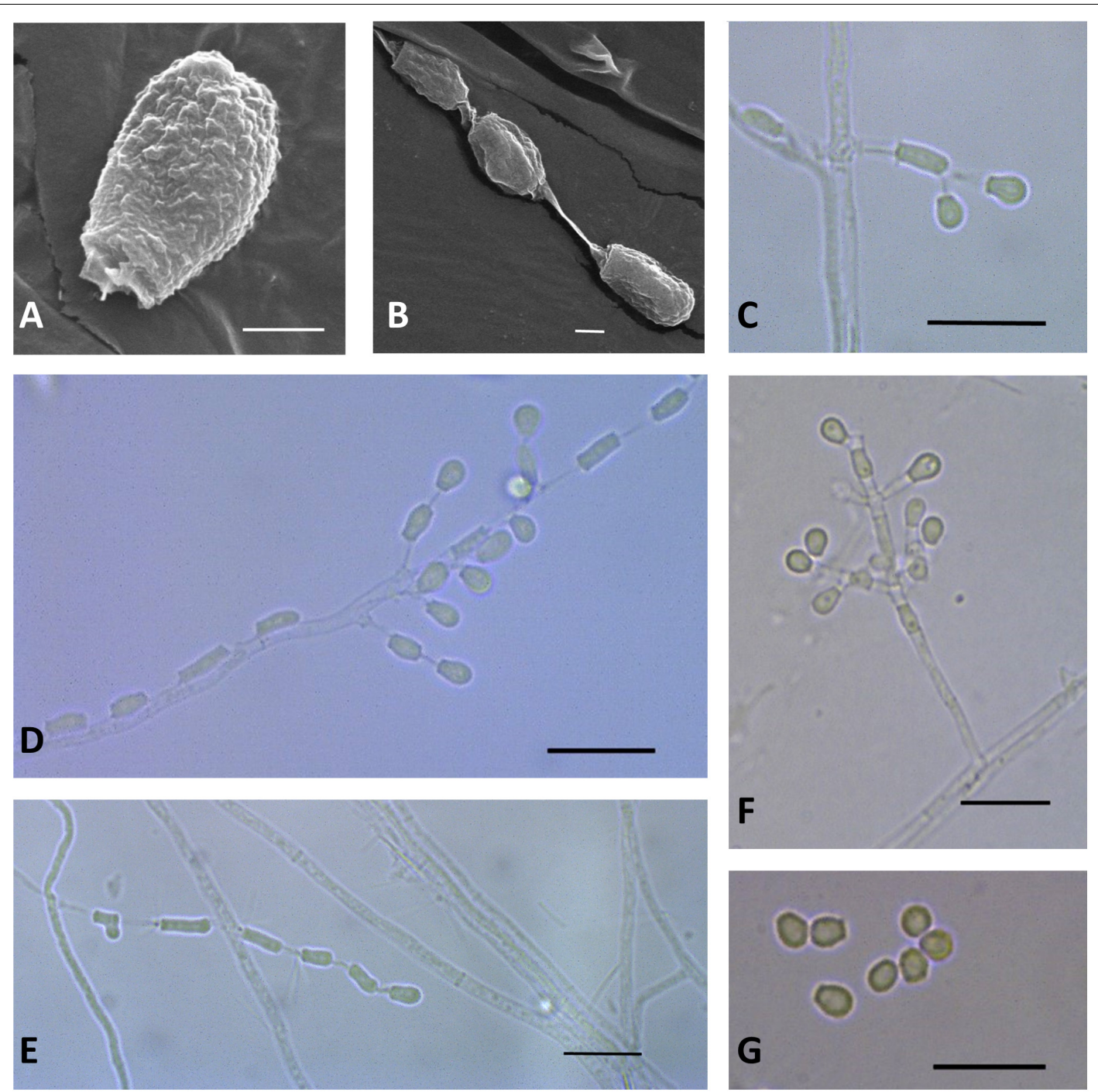

FIGURE 3 | Microscopic analysis of Pseudogymnoascus antarcticus sp. nov. Conidium (A); Fertile hyphae bearing arthroconidia and aleurioconidia, sessile, or stalked (B, C,D,E); Conidiophore (F); Conidia (G). In panels (A,B), the structures were observed using transmission electron microscopy, while in panels (C-G), light microscopy was used. Scale bars $=1 \mu \mathrm{m}(\mathbf{A}, \mathbf{B}), 10 \mu \mathrm{m}$ (C-G).

appressed, colorless to whitish, consisting of immersed, hyaline and somewhat shiny hyphae, diffusible pigments and/or exudates absent; reverse colorless. On SBA, colonies reach $44 \mathrm{~mm}$ in diameter after 28 days at $15^{\circ} \mathrm{C}$, irregular, raised, velvety, with radial grooves, white to beige, filamentous margin, exudates in the form of transparent, cinnamon-color droplets, diffusible pigments not observed; reverse brown. Growth occurs in a range of temperatures on OA, CMA, and SBA. Optimum growth was observed at 15 and $20^{\circ} \mathrm{C}$, and more reduced growth was observed at 5 and $25^{\circ} \mathrm{C}$. No growth was observed at $37^{\circ} \mathrm{C}$.

GenBank accession numbers: ITS $=$ MN417287, LSU $=$ MN417284, MCM7 = MN432491, TEF1 $-\alpha=$ MN418133, RPB2 = MN418137.

Notes: $P$. australis was placed as a member of clade B (Figure 1). Clade B is composed of seven taxa: $P$. shaaxiensis (Zhang et al., 2020) and six other strains that remain unidentified species (RMFC101, 14PA06, 20KY12, 04NY17A, 24MN06, and 11MA08) (Minnis and Lindner, 2013). Phylogenetic analysis clearly shows that $P$. australis forms a distinct lineage with strong support (Figure 1). P. australis can be differentiated from $P$. shaaxiensis by the size and shape of intercalary conidia $(4.7 \times 2.1 \mu \mathrm{m}$, subglobose to elongate and barrelshaped vs. $3.5 \times 3.0 \mu \mathrm{m}$, subglobose, pyriform, or irregularly shaped, respectively). In addition, conidia of $P$. australis may have warts, while conidia of $P$. shaaxiensis are smooth. On the other hand, $P$. australis has fertile hyphae that break into chains of arthroconidia, while $P$. shaaxiensis lacks arthroconidia. Finally, phylogenetic analysis suggested that $P$. australis and the novel species $P$. griseus (see below) are related (Figure 1). However, they can be distinguished based on several morphological characteristics, which are detailed in the protologue of $P$. griseus (see below). 


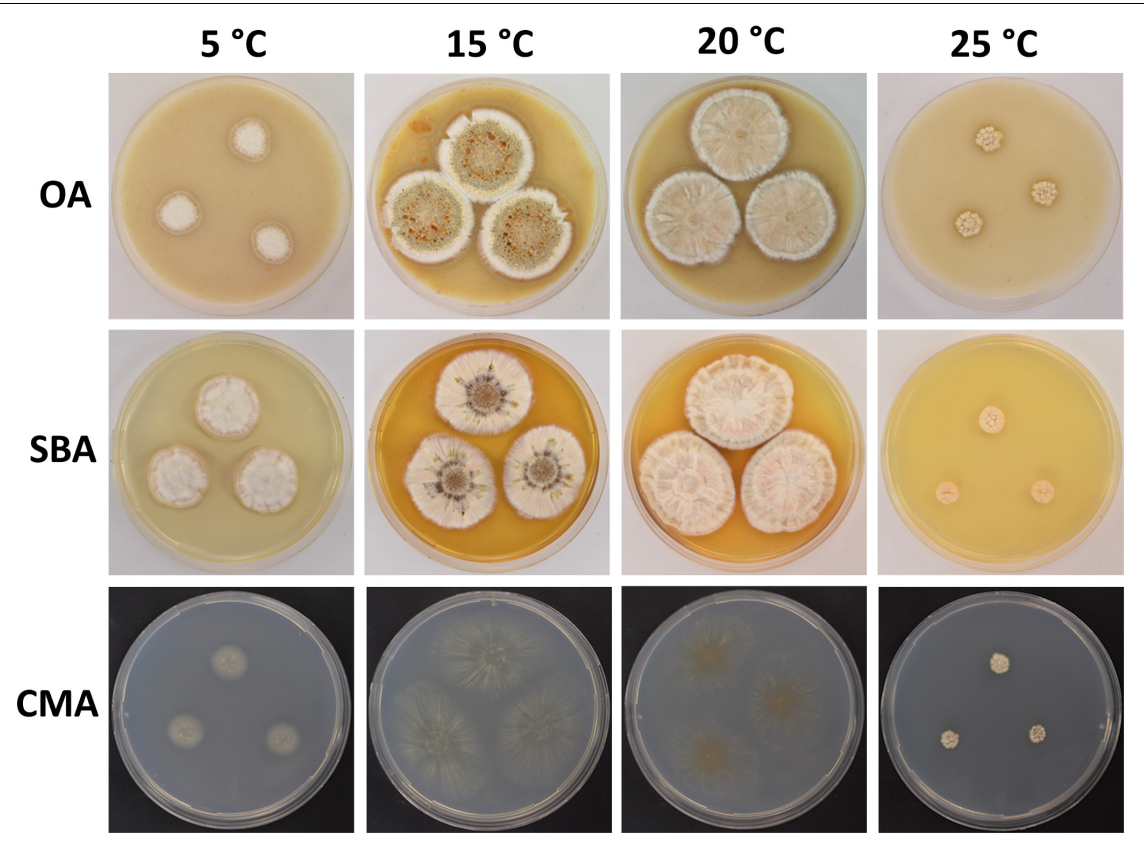

FIGURE 4 | Colony morphology of Pseudogymnoascus australis sp. nov. grown on OA, SBA, and $\mathrm{CMA}$ media at $5,15,20$, and $25^{\circ} \mathrm{C}$ after 28 days of incubation.

\section{Pseudogymnoascus griseus Vaca \& R. Chávez, sp. nov.}

MycoBank number: MB 838969 (Figures 6, 7).

Etymology: The name refers to the gray coloration of the colonies and conidia of this fungus.

Typus: Antarctica, South Shetland archipelago, King George Island, Fildes Bay, from a marine sponge, 7 Dic. 2009, I. Vaca F09-T18-14 (holotype CHFC-EA 568, stored in a metabolically inactive state in Chilean Fungal Collection).

Description: Hyphae forming bundles with two to eight hyphae oriented in parallel, branched, septate, hyaline, smooth, 1.6-2.3 $\mu \mathrm{m}$ wide. Some lateral hyphae end in short chains of arthroconidia, lonely aleurioconidia on fertile hyphae, sessile, or stalked. Conidiophores abundant, erect or geniculated, hyaline, smooth, arising laterally from the hyphae, usually bearing verticils of two to four branches arising from the stipe at an acute angle. Conidia abundant in SBA and CMA, intercalary or terminal, gray to olive green, hyaline, verrucose. Aleurioconidia obovoid to subglobose, occasionally clavate, with broad truncate basal scar, 3.1-4.8 $\times 2.0-4.0 \mu \mathrm{m}(a v=3.8 \times 2.8 \mu \mathrm{m}, n=50)$, in conidiophores separated by connective cells. Intercalary conidia are similar to arthroconidia in shape and size. Arthroconidia intercalary, subglobose to elongate, and barrel-shaped, 3.5$9.6 \times 1.7-3.9 \mu \mathrm{m}(a v=5.7 \times 2.7 \mu \mathrm{m}, n=50)$, separated by connective cells that undergo rhexolysis, some adhering in pairs. Ascomata absent.

Culture characteristics: On $\mathrm{OA}$, colonies reach $40 \mathrm{~mm}$ in diameter after 28 days at $15^{\circ} \mathrm{C}$, round, slightly irregular, raised, floccose, gray, white at the center and the outermost part of the colony, margin white and filiform, abundant exudates in the form of transparent droplets of large size, diffusible pigments not observed; reverse gray. On CMA, colonies reach $45 \mathrm{~mm}$ in diameter after 28 days at $15^{\circ} \mathrm{C}$, filamentous, flat, consisting of immersed and hyaline hyphae, cottony and white at the center, small spots of cottony aerial mycelium emerging in the outermost part of the colony, exudate transparent and scarce, diffusible pigments absent; reverse beige. On SBA, colonies reach $42 \mathrm{~mm}$ in diameter after 28 days at $15^{\circ} \mathrm{C}$, irregular, raised, floccose, smooth at the center, with radially and cerebriform grooves, beige to yellow and gray, notoriously gray into the grooves, margin irregular and filiform, exudate transparent at the center, diffusible pigments absent; reverse brown. Growth occurs in a range of temperatures on OA, CMA, and SBA. Optimum growth was observed at 15 and $20^{\circ} \mathrm{C}$, and more reduced growth was observed at 5 and $25^{\circ} \mathrm{C}$. No growth was observed at $37^{\circ} \mathrm{C}$.

GenBank accession numbers: ITS $=$ MN417288, LSU $=$ MN417285, MCM7 = MN432492, TEF1- $\alpha=$ MN418134, RPB2 = MN418138.

Notes: $P$. griseus is phylogenetically related to $P$. australis; however, the two species are separated with strong bootstrap support (Figure 1). In addition, they are distinguished by the appearance of the colonies on SBA: colonies of $P$. griseus are floccose, gray, and produce transparent exudates, while colonies of $P$. australis are velvety, white to beige, and produce cinnamoncolor exudates. P. griseus and P. australis also differ in the color, ornamentation, and size of conidia. Conidia from $P$. griseus are gray to olive green and verrucose, while conidia from $P$. australis are smooth to irregularly warty and off-white en masse. Aleurioconidia of $P$. griseus are smaller than those of $P$. australis $(3.8 \times 2.8 \mu \mathrm{m}$ vs. $4.2 \times 2.8 \mu \mathrm{m})$; in contrast, arthroconidia of $P$. griseus are larger than those of $P$. australis $(5.7 \times 2.7$ vs. $4.7 \times 2.1 \mu \mathrm{m})$. With respect to $P$. shaaxiensis (Zhang et al., 2020), P. griseus can be differentiated by its gray, verrucose, subglobose to elongate, and barrel-shaped intercalary conidia 

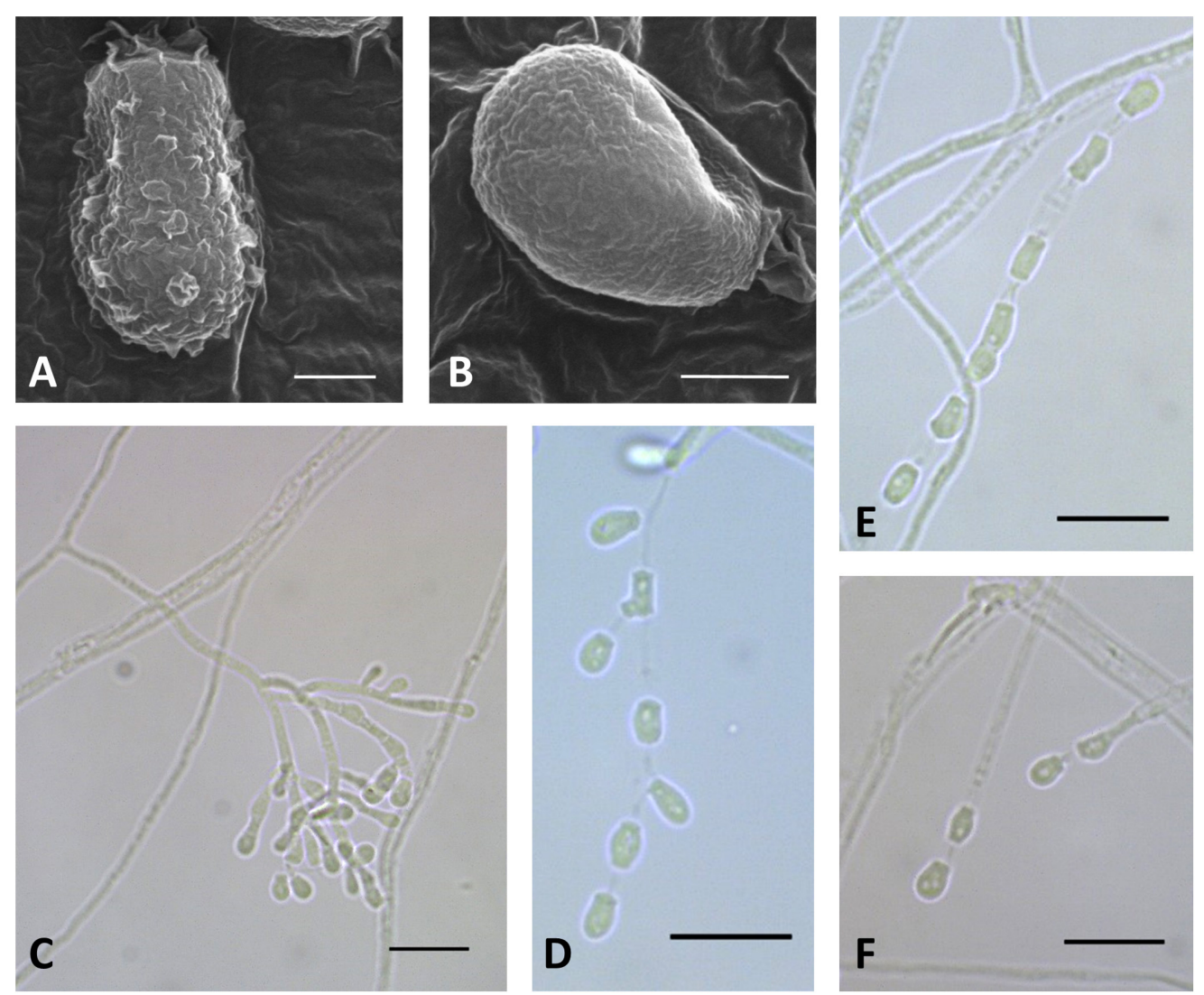

FIGURE 5 | Microscopic analysis of Pseudogymnoascus australis sp. nov. Conidia (A,B); Conidiophore (C); Fertile hyphae bearing arthroconidia and aleurioconidia, sessile, or stalked (D,E,F). In panels (A,B), the structures were observed using transmission electron microscopy, while in panels (C-F), light microscopy was used. Scale bars $=1 \mu \mathrm{m}(\mathbf{A}, \mathbf{B}), 10 \mu \mathrm{m}(\mathbf{C}-\mathbf{F})$.

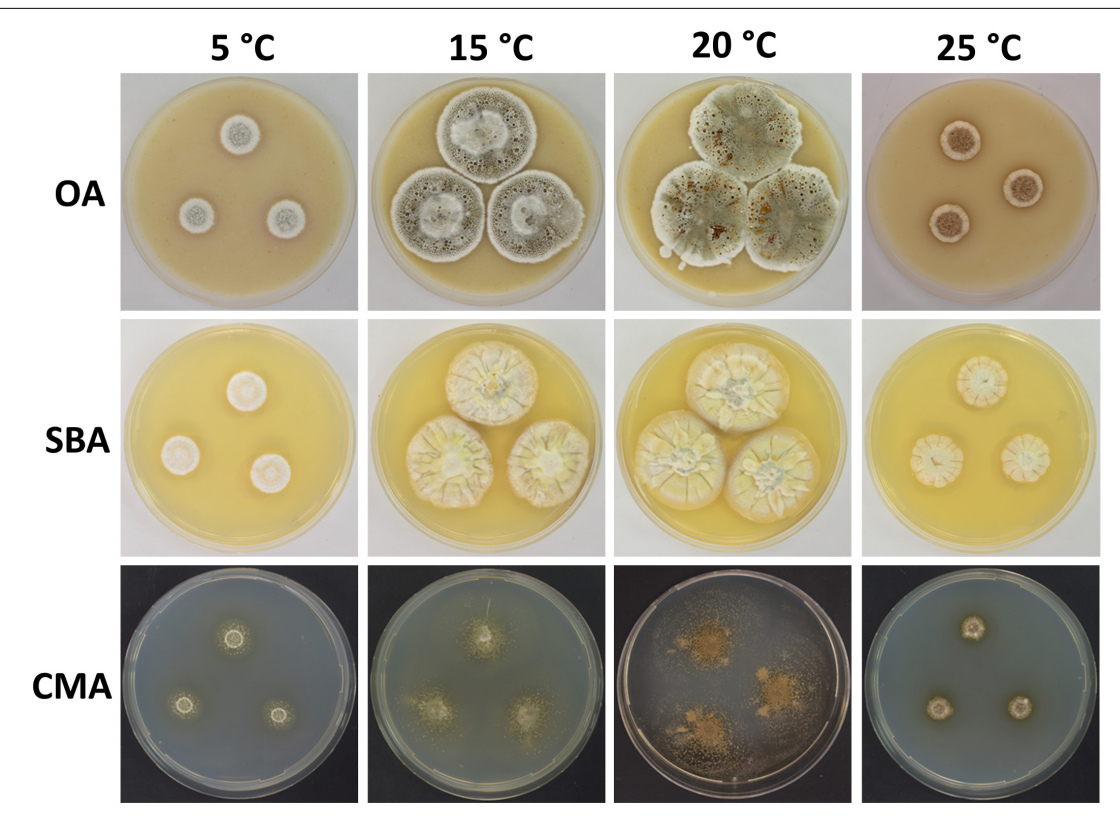

FIGURE 6 | Colony morphology of Pseudogymnoascus griseus sp. nov. grown on OA, SBA, and CMA media at 5, 15, 20, and $25^{\circ} \mathrm{C}$ after 28 days of incubation. 

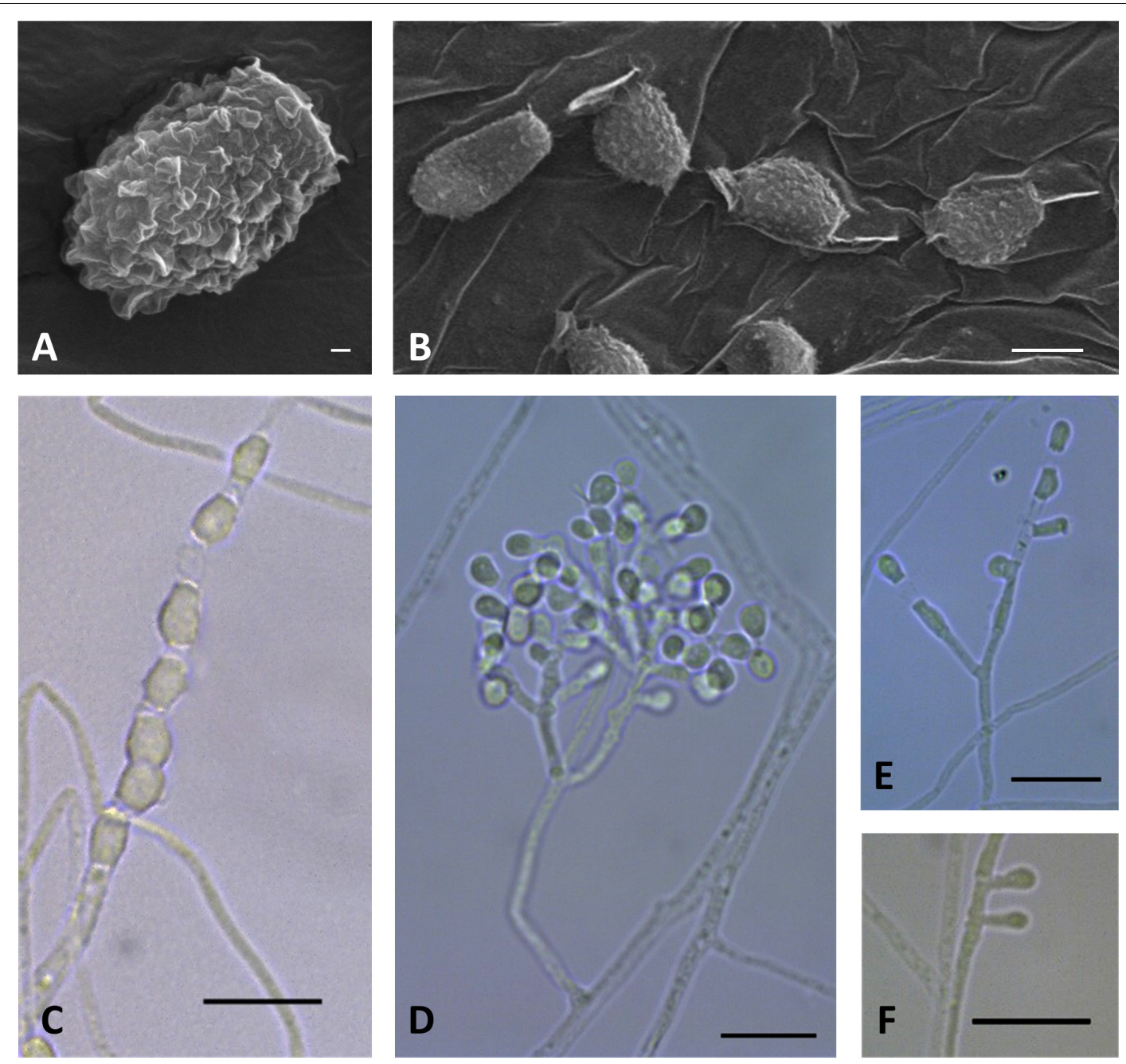

FIGURE 7 | Microscopic analysis of Pseudogymnoascus griseus sp. nov. Conidium (A); Chain of arthroconidia (B,C); Conidiophore (D); Fertile hyphae bearing arthroconidia and aleurioconidia sessile or stalked (E); Lonely stalked aleurioconidia (F). In panels $(\mathbf{A}, \mathbf{B})$, the structures were observed using transmission electron microscopy, while in panels (C-F), light microscopy was used. Scale bars $=200 \mathrm{~nm}$ (A), $2 \mu \mathrm{m}$ (B), and $10 \mu \mathrm{m}$ (C-F).

(the intercalary conidia of $P$. shaaxiensis are colorless, smooth, subglobose, pyriform, or irregularly shaped). Another important difference is that $P$. shaaxiensis lacks chains of arthroconidia, which are abundant in $P$. griseus.

\section{Pseudogymnoascus lanuginosus Vaca \& R. Chávez, sp. nov.}

MycoBank number: MB 838970 (Figures 8, 9).

Etymology: The name refers to the woolly appearance of the colonies.

Typus: Antarctica, South Shetland archipelago, King George Island, Fildes Bay, from a marine sponge, 7 Dic. 2009, I. Vaca F09-T18-27 (holotype CHFC-EA 570, stored in a metabolically inactive state in Chilean Fungal Collection).

Description: Hyphae forming abundant bundles with three to eight hyphae oriented in parallel, branched, septate, hyaline, smooth, 0.9-1.4 $\mu \mathrm{m}$ wide. Spiral hyphae are usually found.
Fertile hyphae bearing arthroconidia and/or aleurioconidia, sessile, or stalked. Conidiophores sparse, solitary, sometimes minimally differentiated from hyphae, hyaline, smooth, arising from the hyphae erect or geniculated, usually bearing verticils of two to four branches at an acute angle. Conidia absent in SBA, abundant in CMA, intercalary or terminal, variable in size and shape, off-white en masse, hyaline, tuberculate, sparsely ornamented with minute warts; preponderance of intercalary arthroconidia. Aleurioconidia clavate, occasionally obovoid to subglobose, with the apex rounded and broad truncate basal scar, 2.2-5.3 $\times 2.1-$ $3.1 \mu \mathrm{m}(a v=4.3 \times 2.6 \mu \mathrm{m}, n=50)$. Intercalary conidia are similar to arthroconidia in shape and size. Arthroconidia intercalary, barrel-shaped or cylindrical, $4.9-14.5 \times 1.4-2.3 \mu \mathrm{m}$ $(a v=8.6 \times 1.7 \mu \mathrm{m}, n=50)$, separated by connective cells that undergo rhexolysis; occasionally bearing sessile conidia; arthroconidia formed in hyphae junctions are L- or boot-shaped. Ascomata absent. 


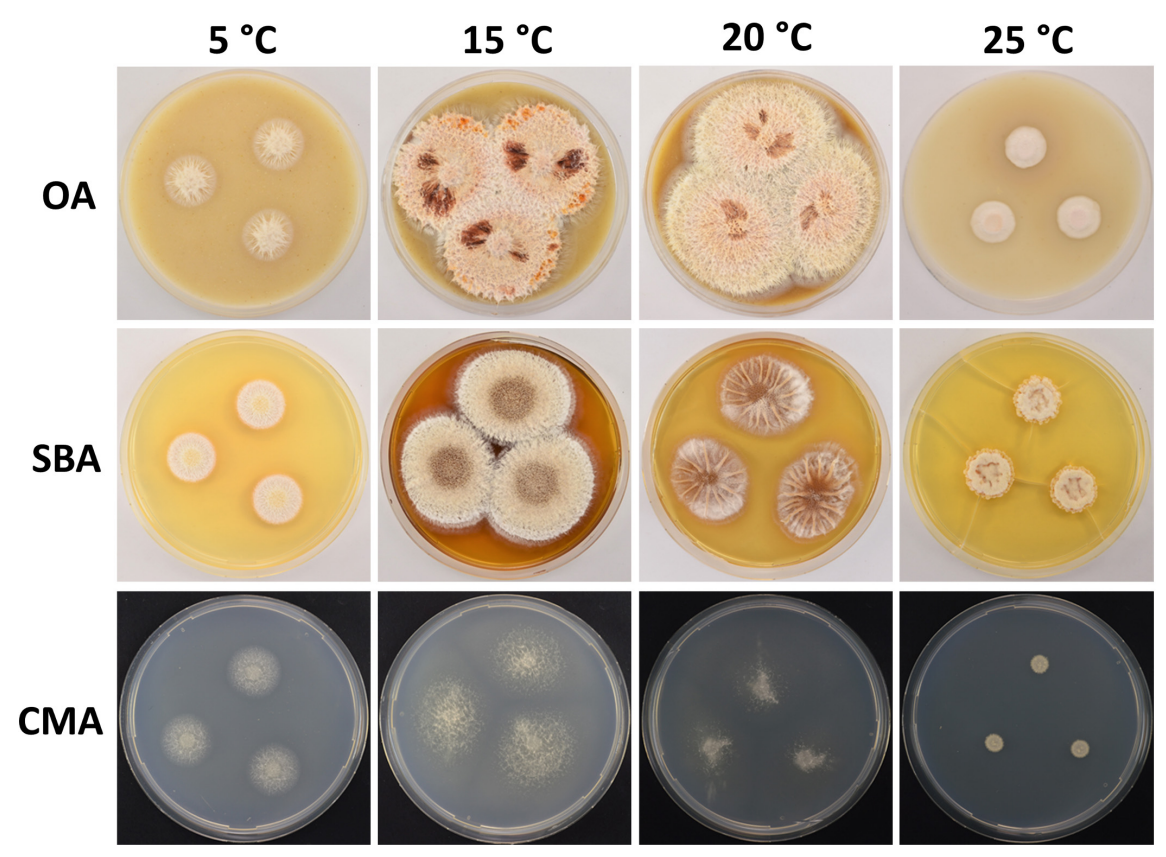

FIGURE 8 | Colony morphology of Pseudogymnoascus lanuginosus sp. nov. grown on $\mathrm{OA}$, SBA, and $\mathrm{CMA}$ media at $5,15,20$, and $25^{\circ} \mathrm{C}$ after 28 days of incubation. The cracked agar observed in SBA at $25^{\circ} \mathrm{C}$ was not produced by a technical pitfall, but was produced by the growth of the fungus. Apparently, under these conditions, the fungus extracts most moisture, contracts agar, and cracks it. This was always observed in this medium at this temperature.

Culture characteristics: On OA, colonies reach $45 \mathrm{~mm}$ in diameter after 28 days at $15^{\circ} \mathrm{C}$, irregular, raised, aerial mycelium abundant, appearing as woolly tufts, pale pink to brown, margin white and filamentous, abundant exudates in the form of droplets of cinnamon or brick-red color, diffusible pigments absent; reverse brown. On CMA, colonies reach $45 \mathrm{~mm}$ in diameter after 28 days at $15^{\circ} \mathrm{C}$, round, flat, cottony, white, consisting of immersed and hyaline hyphae, exudates and diffusible pigments absent; reverse white. On SBA, colonies reach $45 \mathrm{~mm}$ in diameter after 28 days at $15^{\circ} \mathrm{C}$, round, raised, aerial mycelium abundant, appearing as woolly tufts, surface with concentric circles brown, beige, and white (from center to edge), margin entire and filamentous, exudates absent, soluble pigment cinnamon; reverse brown in center, white in outer region. Growth occurs in a range of temperatures on $\mathrm{OA}, \mathrm{CMA}$, and SBA. Optimum growth was observed at 15 and $20^{\circ} \mathrm{C}$, and more reduced growth was observed at 5 and $25^{\circ} \mathrm{C}$. No growth was observed at $37^{\circ} \mathrm{C}$.

GenBank accession numbers: ITS $=$ MN417286, LSU $=$ MN417283, MCM7 = MN418139, TEF1 $-\alpha=$ MN418132, $\mathrm{RPB} 2$ = MN418136.

Notes: P. lanuginosus was placed as the most basal member of clade $\mathrm{E}$ (Figure 1). Clade $\mathrm{E}$ is composed of four strains that remain unidentified species $(01 \mathrm{NH} 08,04 \mathrm{NY} 16,24 \mathrm{MN} 13$, and VKM F-103) (Minnis and Lindner, 2013; Leushkin et al., 2015) and P. verrucosus (Rice and Currah, 2006). Phylogenetic analysis clearly shows that $P$. lanuginosus forms a distinct lineage with strong support (Figure 1). P. lanuginosus can be differentiated from $P$. verrucosus by the absence of ascomata, the woolly appearance and the pink coloration of its colonies on OA, and its more elongated arthroconidia $(8.6 \times 1.7 \mu \mathrm{m}$ vs. $2.5-5 \times 2-$ $3 \mu \mathrm{m})$.

\section{DISCUSSION}

Pseudogymnoascus is a fungal genus frequently found in terrestrial and marine samples collected in Antarctica (Santiago et al., 2015; Gomes et al., 2018; Rosa et al., 2019; Carvalho et al., 2020; Ogaki et al., 2020a,b; Rosa et al., 2020). Most of the Pseudogymnoascus isolates obtained from these samples have not been identified to the species level. To date, novel species of Pseudogymnoascus of Antarctic origin have not been described. Hence, the four new species $P$. antarcticus, $P$. australis, $P$. griseus, and P. lanuginosus described in this work represent the first four species of Pseudogymnoascus from Antarctica and the Southern Hemisphere.

The new species were characterized through phylogenetic and morphological analyses. The phylogenetic analyses support the placement of $P$. australis and $P$. griseus as members of clade B of Pseudogymnoascus, which also includes $P$. shaaxiensis, the only species thus far described within this clade (Figure 1). The three species share the absence of ascomata as a common characteristic, suggesting, in principle, that clade B could harbor strains of Pseudogymnoascus that do not present sexual structures. An analysis of the sexual development of additional strains of this clade is required to confirm this hypothesis. Concerning ecological characteristics, all of the current members of clade $\mathrm{B}$ were isolated from soil samples from different origins: bat hibernacula soil in the eastern United States (strains 14PA06, 

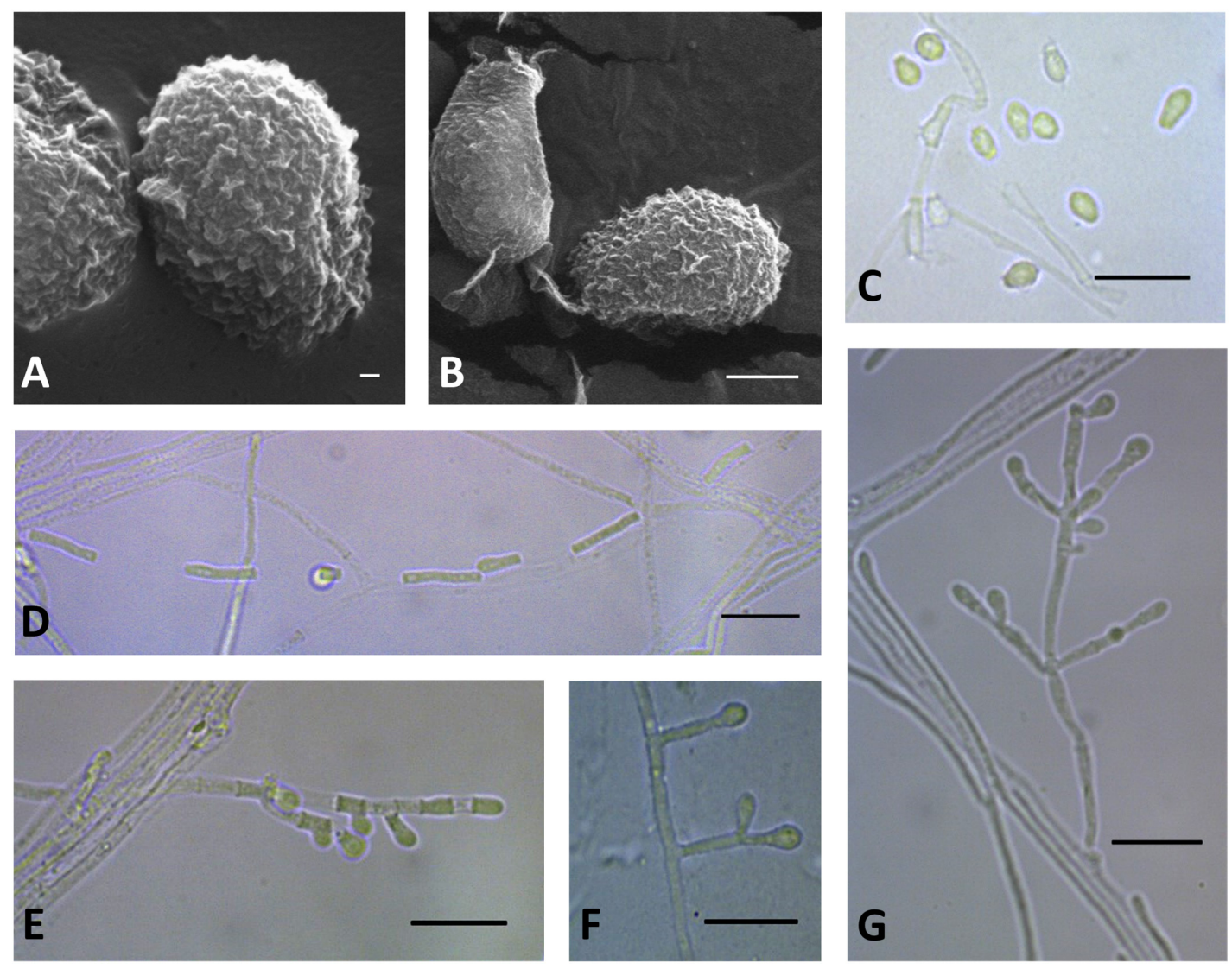

FIGURE 9 | Microscopic analysis of Pseudogymnoascus lanuginosus sp. nov. Conidia (A,B,C); Chain of arthroconidia (D); Fertile hyphae bearing arthroconidia and aleurioconidia, sessile, or stalked (E); Stalked aleurioconidia (F); Conidiophore $\mathbf{( G ) . ~ I n ~ p a n e l s ~}(\mathbf{A}, \mathbf{B})$, the structures were observed using transmission electron microscopy, while in panels (C-G), light microscopy was used. Scale bars $=200 \mathrm{~nm}$ (A), $1 \mu \mathrm{m}$ (B), and $10 \mu \mathrm{m}$ (C-G).

20KY12, 04NY17A, 24MN06, and 11MA08; Lorch et al., 2013), desert grassland soil in Utah (RMFC101; Minnis and Lindner, 2013) and epiphytic soil in China (P. shaaxiensis; Zhang et al., 2020). In contrast, $P$. australis and $P$. griseus were obtained from Antarctic marine sponges. As a member of class Leotiomycetes, Pseudogymnoascus is expected to have a worldwide distribution in diverse environments, including soil, fresh and marine water, or air (Johnston et al., 2019). Therefore, the placement of $P$. australis and $P$. griseus in clade B suggests that the diversity currently represented in clade B would be only a small fraction of the total diversity of Pseudogymnoascus of this clade.

Pseudogymnoascus lanuginosus was placed as a member of clade E of Pseudogymnoascus. This clade also includes strains 01NH08, 04NY16, 24MN13, and VKM F-103, and the species $P$. verrucosus (Rice and Currah, 2006; Minnis and Lindner, 2013; Leushkin et al., 2015). Unlike P. lanuginosus, P. verrucosus produces ascomata (Rice and Currah, 2006), indicating that clade E could harbor species of Pseudogymnoascus that do or do not produce sexual structures. This is in agreement with previous observations by Minnis and Lindner (2013), who noted that $P$. destructans, a species where the sexual stage has not been observed, was placed among a number of lineages with known sexual stages. Regarding the ecological origin of strains within clade E, P. verrucosus was isolated from a brown-rotted black spruce wood found in a Sphagnum bog in the southern boreal forest of western Canada (Rice and Currah, 2006), strain VKM F103 was isolated from soil in New York, United States (Leushkin et al., 2015), and strains 01NH08, 04NY16, and 24MN13 were isolated from bat hibernacula soil in the eastern United States (Lorch et al., 2013). Therefore, clade E harbors a diverse group of Pseudogymnoascus that includes wood-degrading fungi, soil fungi, and fungi associated with marine sponges.

Finally, the phylogenetic position of $P$. antarcticus shows that this species represents an independent lineage, which is related to clade I. This clade includes three strains (18VA12, 18VA13, and 15PA11) isolated from bat hibernacula soil in the eastern United States (Lorch et al., 2013), and strain VKM F4246 isolated from coniferous litter in Selenge Aimag, Mongolia (Leushkin et al., 2015), which remain undescribed species. Thus, the diversity of Pseudogymnoascus currently represented in clade I is limited and an analysis of additional strains is required to reveal the total diversity of this clade.

It is interesting to note that none of the new species described in this work present sexual structures. In Ascomycota, sexual reproduction is often difficult to detect under laboratory conditions (Ni et al., 2011). In the case of Pseudogymnoascus, 
some species produce sexual structures (Rice and Currah, 2006; Crous et al., 2019; Crous et al., 2020). However, a significant number of strains of Pseudogymnoascus, including some accepted species, have not shown evidence of sexual reproduction (Chatuverdi et al., 2010; Leushkin et al., 2015; Zhang et al., 2020).

Asexual structures of the new species usually consist of conidiophores bearing intercalary and terminal conidia, lonely aleurioconidia, and chains of arthroconidia. Conidiophores bearing intercalary and terminal conidia are a general characteristic observed in several species of Pseudogymnoascus. In contrast, chains of arthroconidia have been previously observed only in P. appendiculatus (Rice and Currah, 2006) and P. destructans (Gargas et al., 2009). Most Pseudogymnoascus species have hyaline or white to off-white conidia en masse. Thus, the gray to olive green conidia observed in the new species $P$. griseus are a singular characteristic that has not previously been reported in other species of the genus. P. lanuginosus can be easily distinguished by its larger arthroconidia. Finally, $P$. antarcticus grows at $37^{\circ} \mathrm{C}$, a physiological characteristic that has only been reported before for $P$. caucasicus (Cejp and Milko, 1966).

More research is necessary to achieve a full picture of the taxonomy of Pseudogymnoascus of Antarctic origin. In this context, our findings represent a first step, opening the opportunity for the description of additional new species of Pseudogymnoascus by other researchers working on fungi from Antarctica.

\section{AUTHOR'S NOTE}

While this manuscript was in review, Zhang et al. (2021) reported other four new species of Pseudogymnoascus, isolated from soil in China ( $P$. catenatus, $P$. fujianensis, $P$. yunnanensis, and $P$. zhejiangensis). Our species are different to those described in the paper of Zhang et al. (2021).

\section{DATA AVAILABILITY STATEMENT}

The datasets presented in this study can be found in online repositories. The names of the repository/repositories and

\section{REFERENCES}

Blehert, D. S., Hicks, A. C., Behr, M. J., Meteyer, C. U., Berlowski-Zier, B. M., Buckles, E. L., et al. (2009). Bat white-nose syndrome: an emerging fungal pathogen? Science 323:227. doi: 10.1126/science.1163874

Carvalho, C., Ferreira, M., Gonçalves, V., Santos, A. R., Carvalho-Silva, M., Camara, P., et al. (2020). Cultivable fungi associated with bryosphere of bipolar mosses Polytrichastrum alpinum alpinum and Polytrichum juniperinum in Antarctica. Polar Biol. 43, 545-553. doi: 10.1007/s00300-020-02658-7

Cejp, G. F., and Milko, A. A. (1966). Genus pseudogymnoascus raillo (gymnoascaceae). Ėeská Mykologie 20, 160-163.

Chatuverdi, V., Springer, D. J., Behr, M. J., Ramani, R., Li, X., Peck, M. K., et al. (2010). Morphological and molecular characterizations of psychrophilic fungus geomyces destructans from New York bats with white-nose syndrome (WNS). PLoS One 5:e10783. doi: 10.1371/journal.pone.0010783

Costa Coelho, L., Carvalho, C., Rosa, C., and Rosa, L. (2021). Diversity, distribution, and xerophilic tolerance of cultivable fungi associated with the accession number(s) can be found in the article/Supplementary Material.

\section{AUTHOR CONTRIBUTIONS}

IV and RC were responsible for conceptualization and drafted the manuscript. IV, FL, EÁ, and GV designed the experiments. $\mathrm{PV}, \mathrm{GV}, \mathrm{VO}, \mathrm{AD}$, and CG-D performed all laboratory analysis and evaluated the data. PV was responsible for data curation and software. All authors contributed to the article and approved the submitted version.

\section{FUNDING}

This research was funded by Instituto Antártico Chileno (INACH), grant INACH RG_15-14, and Agencia Nacional de Investigación y Desarrollo, Ministerio de Ciencia, Tecnología, Conocimiento e Innovación, Gobierno de Chile, grant ANID - Fondecyt de Postdoctorado 2021 - N 3210135. VO was supported by doctoral fellowship CONICYTPFCHA/Doctorado Nacional/2018-21181056. PV was supported by grant Instituto Antártico Chileno (INACH) MG_07-20. RC was supported by DICYT-USACH.

\section{ACKNOWLEDGMENTS}

The authors are grateful to Marco Méndez for his advice on phylogeny, Gloria Levicán for her support in microscopy analyses, and Maria Inés Polanco for her technical support.

\section{SUPPLEMENTARY MATERIAL}

The Supplementary Material for this article can be found online at: https://www.frontiersin.org/articles/10.3389/fmicb. 2021.713189/full\#supplementary-material

Antarctic angiosperms. Polar Biol. 44, 379-388. doi: 10.1007/s00300-02102799-3

Crous, P. W., Cowan, D. E., Maggs-Kolling, G., Yilmaz, N., Larsson, E., Angelini, C., et al. (2020). Fungal planet description sheets 1112-1181. Persoonia 45, 251-409. doi: 10.3767/persoonia.2020.45.10

Crous, P. W., Wingfield, M. J., Lombard, L., Roets, F., Swart, W. J., Alvarado, P., et al. (2019). Fungal planet description sheets 951-1041. Persoonia 43, 223-425. doi: 10.3767/persoonia.2019.43.06

Durán, P., Barra, P. J., Jorquera, M. A., Viscardi, S., Fernandez, C., Paz, C., et al. (2019). Occurrence of soil fungi in Antarctic pristine environments. Front. Bioeng. Biotechnol. 7:28. doi: 10.3389/fbioe.2019.00028

Furbino, L. E., Godinho, V. M., Santiago, I. F., Pellizari, F. M., Alves, T. M., Zani, C. L., et al. (2014). Diversity patterns, ecology and biological activities of fungal communities associated with the endemic macroalgae across the Antarctic peninsula. Microb. Ecol. 67, 775-787. doi: 10.1007/s00248-014-0374-9

Furbino, L., Pellizzari, F. M., Neto, P. C., Rosa, C. A., and Rosa, L. H. (2018). Isolation of fungi associated with macroalgae from maritime Antarctica and 
their production of agarolytic and carragenolytic activities. Polar Biol. 41, 527-535. doi: 10.1007/s00300-017-2213-1

Gargas, A., Trest, M. T., Christensen, M., Volk, T. J., and Blehert, D. S. (2009). Geomyces destructans sp. nov. associated with bat white-nose syndrome. Mycotaxon 108, 147-154. doi: 10.5248/108.147

Gil-Durán, C., Rojas-Aedo, J. F., Medina, E., Vaca, I., García-Rico, R. O., Villagrán, S., et al. (2015). The pczl gene, which encodes a $\mathrm{Zn}(\mathrm{II}) 2 \mathrm{Cys} 6$ protein, is involved in the control of growth, conidiation, and conidial germination in the filamentous fungus Penicillium roqueforti. PLoS One 10:e0120740. doi: 10.1371/journal.pone.0120740

Godinho, V. M., Furbino, L. E., Santiago, I. F., Pellizzari, F. M., Yokoya, N., Pupo, D., et al. (2013). Diversity and bioprospecting of fungal communities associated with endemic and cold-adapted macroalgae in Antarctica. ISME J. 7, 1434-1451. doi: 10.1038/ismej.2013.77

Godinho, V. M., Gonçalves, V. N., Santiago, I. F., Figueredo, H. M., Vitoreli, G. A., Schaefer, C. E. G. R., et al. (2015). Diversity and bioprospection of fungal community present in oligotrophic soil of continental Antarctica. Extremophiles 19, 585-596. doi: 10.1007/s00792-015-0741-6

Gomes, E. C. Q., Godinho, V. M., Silva, D. A. S., de Paula, M. T. R., Vitoreli, G. A., Zani, C. L., et al. (2018). Cultivable fungi present in Antarctic soils: taxonomy, phylogeny, diversity, and bioprospecting of antiparasitic and herbicidal metabolites. Extremophiles 22, 381-393. doi: 10.1007/s00792-0181003-1

Gonçalves, V. N., Vaz, A. B., Rosa, C. A., and Rosa, L. H. (2012). Diversity and distribution of fungal communities in lakes of Antarctica. FEMS Microbiol. Ecol. 82, 459-471. doi: 10.1111/j.1574-6941.2012.01424.x

Gupta, P., Vakhlu, J., Sharma, Y. P., Imchen, M., and Kumavath, R. (2020). Metagenomic insights into the fungal assemblages of the northwest himalayan cold desert. Extremophiles 24, 749-758. doi: 10.1007/s00792-020-01191-z

Henríquez, M., Vergara, K., Norambuena, J., Beiza, A., Maza, F., Ubilla, P., et al. (2014). Diversity of cultivable fungi associated with Antarctic marine sponges and screening for their antimicrobial, antitumoral and antioxidant potential. World J. Microbiol. Biotechnol. 30, 65-76. doi: 10.1007/s11274-013-1418-x

Johnston, P. R., Quijada, L., Smith, C. A., Baral, H. O., Hosoya, T., Baschien, C., et al. (2019). A multigene phylogeny toward a new phylogenetic classification of leotiomycetes. IMA Fungus 10:1. doi: 10.1186/s43008-019-0002-x

Kalyaanamoorthy, S., Minh, B. Q., Wong, T. K. F., von Haeseler, A., and Jermiin, L. S. (2017). Model finder: fast model selection for accurate phylogenetic estimates. Nat. Methods 14, 587-589. doi: 10.1038/nmeth.4285

Katoh, K., and Standley, D. M. (2013). MAFFT multiple sequence alignment software version 7: improvements in performance and usability. Mol. Biol. Evol. 30, 772-780. doi: $10.1093 / \mathrm{molbev} / \mathrm{mst} 010$

Leushkin, E. V., Logacheva, M. D., Penin, A. A., Sutormin, R. A., Gerasimov, E. S., Kochkina, G. A., et al. (2015). Comparative genome analysis of Pseudogymnoascus spp. reveals primarily clonal evolution with small genome fragments exchanged between lineages. BMC Genom. 16:400. doi: 10.1186/ s12864-015-1570-9

Lorch, J. M., Lindner, D. L., Gargas, A., Muller, L. K., Minnis, A. M., and Blehert, D. S. A. (2013). Culture-based survey of fungi in soil from bat hibernacula in the eastern united states and its implications for detection of Geomyces destructans, the causal agent of bat white-nose syndrome. Mycologia 105, 237-252. doi: $10.3852 / 12-207$

Maddison, W. P., and Maddison, D. R. (2019). Mesquite: a Modular System for Evolutionary Analysis. Version 3.61.

Mahuku, G. (2004). A simple extraction method suitable for PCR-based analysis of plant, fungal, and bacterial DNA. Plant Mol. Biol. Rep. 22, 71-81. doi: 10.1007/BF02773351

Minh, Q., Nguyen, M., and von Haeseler, A. A. (2013). Ultrafast approximation for phylogenetic bootstrap. Mol. Biol. Evol. 30, 1188-1195. doi: 10.1093/molbev/ mst024

Minnis, A. M., and Lindner, D. L. (2013). Phylogenetic evaluation of geomyces and allies reveals no close relatives of Pseudogymnoascus destructans, comb. nov., in bat hibernacula of eastern North America. Fungal Biol. 117, 638-649. doi: 10.1016/j.funbio.2013.07.001

Müller, E., and von Arx, J. A. (1982). Pseudogymnoascus alpinus, nov. spec. Sydowia $35,135-137$.
Nguyen, L.-T., Schmidt, H. A., von Haeseler, A., and Minh, B. Q. (2015). I Q-tree: a fast and effective stochastic algorithm for estimating maximum likelihood phylogenies. Mol. Biol. Evol. 32, 268-274. doi: 10.1093/molbev/msu300

Ni, M., Feretzaki, M., Sun, S., Wang, X., and Heitman, J. (2011). Sex in fungi. Annu. Rev. Genet. 45, 405-430. doi: 10.1146/annurev-genet-110410-132536

Ogaki, M. B., Coelho, L. C., Vieira, R., Neto, A., Zani, C., Alves, T., et al. (2020a). Cultivable fungi present in deep-sea sediments of Antarctica: taxonomy, diversity, and bioprospecting of bioactive compounds. Extremophiles 24, 227238. doi: 10.1007/s00792-019-01148-x

Ogaki, M. B., Teixeira, D. R., Vieira, R., Lírio, J. M., Felizardo, J. P. O., Abuchacra, R. C., et al. (2020b). Diversity and bioprospecting of cultivable fungal assemblages in sediments of lakes in the Antarctic peninsula. Fungal Biol. 124, 601-611. doi: 10.1016/j.funbio.2020.02.015

Ogaki, M. B., Pinto, O. H. B., Vieira, R., Neto, A. A., Convey, P., Carvalho-Silva, M., et al. (2021). Fungi present in Antarctic deep-sea sediments assessed using DNA metabarcoding. Microb. Ecol. 2021, 1-8. doi: 10.1007/s00248-020-01658-8

Rafiq, M., Nadeem, S., Hassan, N., Hayat, M., Sajjad, W., Zada, S., et al. (2020). Fungal recovery and characterization from Hindu kush mountain range, Tirich Mir glacier, and their potential for biotechnological applications. J. Basic Microbiol. 60, 444-457. doi: 10.1002/jobm.201900608

Raillo, A. (1929). Beiträge zur kenntnis der boden-pilze. Zentralbl Bakteriol. Parasitenkd. Infektionskr. Hyg 78, 515-524.

Rice, A. V., and Currah, R. S. (2006). Two new species of pseudogymnoascus with Geomyces anamorphs and their phylogenetic relationship with Gymnostellatospora. Mycologia 98, 307-318. doi: 10.1080/15572536.2006. 11832703

Robicheau, B., Adams, S., Provencher, J., Robertson, G., Mallory, M., Walker, A., et al. (2019). Diversity and keratin degrading ability of fungi isolated from Canadian Arctic marine bird feathers. Arctic 72, 347-359. doi: 10.14430/ $\operatorname{arctic} 69301$

Ronquist, F., Teslenko, M., van der Mark, P., Ayres, D. L., Darling, A., Höhna, S., et al. (2012). MRBAYES 3.2: efficient bayesian phylogenetic inference and model selection across a large model space. Syst. Biol. 61, 539-542. doi: 10.1093/sysbio/ sys029

Rosa, L. H., Pinto, O. H. B., Šantl-Temkiv, T., Convey, P., Carvalho-Silva, M., Rosa, C. A., et al. (2020). DNA metabarcoding of fungal diversity in air and snow of livingston Island, South shetland Islands, Antarctica. Sci. Rep. 10:21793. doi: 10.1038/s41598-020-78630-6

Rosa, L. H., Zani, C. L., Cantrell, C. L., Duke, S. E., Van Dijck, P., Desideri, A., et al. (2019). "Fungi in Antarctica: diversity, ecology, effects of climate change, and bioprospection for bioactive compounds," in Fungi of Antarctica: Diversity Ecology and Biotechnological Applications, ed. L. H. Rosa (Switzerland: Springer), 1-18. doi: 10.1007/978-3-030-18367-7_1

Samson, R. A. (1972). Notes on Pseudogymnoascus, Gymnoascus and related genera. Acta Bot. Neerl. 21, 517-527. doi: 10.1111/j.1438-8677.1972. tb00804.x

Santiago, I. F., Alves, T. M., Rabello, A., Junior, P. A. S., Romanha, A. J., Zani, C. L., et al. (2012). Leishmanicidal and antitumoral activities of endophytic fungi associated with the Antarctic angiosperms Deschampsia antarctica Desv. and Colobanthus quitensis (kunth) bartl. Extremophiles 16, 95-103. doi: 10.1007/ s00792-011-0409-9

Santiago, I. F., Soares, M. A., Rosa, C. A., and Rosa, L. H. (2015). Lichenosphere: a protected natural microhabitat of the non-lichenized fungal communities living in extreme environments of Antarctica. Extremophiles 19, 1087-1097. doi: 10.1007/s00792-015-0781-y

Santos, J., Meyer, E., and Sette, L. (2020). Fungal community in Antarctic soil along the retreating collins glacier (Fildes Peninsula, King George Island). Microorganisms 8:1145. doi: 10.3390/microorganisms8081145

Swofford, D. L. (2002). PAUP*: Phylogenetic Analysis Using Parsimony (* and Other Methods). Version 4.0b10.

Vieira, G., Puriæ, J., Morão, L. G., Dos Santos, J. A., Inforsato, F. J., Sette, L. D., et al. (2018). Terrestrial and marine Antarctic fungi extracts active against Xanthomonas citri subsp. citri. Lett. Appl. Microbiol. 67, 64-71. doi: 10.1111/ lam. 12890

Wentzel, L. C. P., Inforsato, F. J., Montoya, Q. V., Montoya, Q., Rossin, B., Nascimiento, N., et al. (2019). Fungi from Admiralty bay (king 
George Island, Antarctica) soils and marine sediments. Microb. Ecol. 77, 12-24. doi: 10.1007/s00248-018-1217-x

Zhang, Z., Dong, C., Chen, W., Mou, Q., Lu, X., Han, Y., et al. (2020). The enigmatic thelebolaceae (thelebolales, leotiomycetes): one new genus solomyces and five new species. Front. Microbiol. 11:572596. doi: 10.3389/fmicb. 2020.5

Zhang, Z. Y., Shao, Q. Y., Li, X., Chen, W. H., Liang J. D, Han, Y. F., et al. (2021). Culturable fungi from urban soils in China I: description of 10 new taxa. Microbiol. Spectr. In press. doi: 10.1128/Spectrum.00867-21

Conflict of Interest: The authors declare that the research was conducted in the absence of any commercial or financial relationships that could be construed as a potential conflict of interest.
Publisher's Note: All claims expressed in this article are solely those of the authors and do not necessarily represent those of their affiliated organizations, or those of the publisher, the editors and the reviewers. Any product that may be evaluated in this article, or claim that may be made by its manufacturer, is not guaranteed or endorsed by the publisher.

Copyright (c) 2021 Villanueva, Vásquez, Gil-Durán, Oliva, Díaz, Henríquez, Álvarez, Laich, Chávez and Vaca. This is an open-access article distributed under the terms of the Creative Commons Attribution License (CC BY). The use, distribution or reproduction in other forums is permitted, provided the original author(s) and the copyright owner(s) are credited and that the original publication in this journal is cited, in accordance with accepted academic practice. No use, distribution or reproduction is permitted which does not comply with these terms. 